\title{
Research and Design of Logistics Monitoring System
}

\author{
Jie Huang ${ }^{1, a}$ \\ ${ }^{1}$ College of Mechanical and Electronic Engineering, Hezhou University, Hezhou, China, 542899 \\ ahuangjie0773@163.com
}

Keywords: Logistics monitoring; Zigbee; RFID; GPRS; GPS

\begin{abstract}
In view of the logistics tracking and monitoring, Zigbee technology, RFID technology, GPRS technology and GPS technology are combined in the system. Considering the actual demand of the logistics monitoring system, a logistics monitoring system is designed. In this paper, the principle and design of RFID monitoring node, video monitoring node, access control node and monitoring center are described. The system has been tested. Test results show that the functions and performance indicators meet the design requirements of the system. The logistics monitoring system has the advantages of good stability and convenient operation. It has good application prospects.
\end{abstract}

\section{Introduction}

With the development of society, the logistics industry has also been rapid development. On the one hand, in the course of transportation, the goods are damaged or lost often happen due to human factors or other factors. When the goods are damaged or lost, the reasons need to be found to provide a basis for claims. On the other hand, in the process of transportation, the monitoring center needs to understand and master the monitoring data of logistics vehicles. At present, the logistics monitoring system usually adopts GPS technology to monitor the location information of logistics vehicles. It uses RFID technology to monitor the goods. When the goods are damaged or lost, the reason for the damage or loss of the goods is difficult to be found. Zigbee technology is a short distance, low power consumption and low transmission rate of wireless communication technology. It has been widely used in the field of agricultural monitoring and intelligent monitoring system. RFID is a wireless communication technology. It can identify a specific target and read or write data through the radio. RFID technology has been widely used in access control systems, asset management and logistics monitoring. In this paper, a logistics monitoring system was studied and designed by combining Zigbee technology, RFID technology, GPRS technology and GPS technology. The system can monitor the goods accurately and timely. It can also carry out video surveillance of goods.

\section{System Principle and Hardware Design}

System Structure. The system consists of RFID monitoring node, access control node, video monitoring node, coordinators and monitoring center. The Zigbee wireless technology is used to build the network in the RFID monitoring node, the access control node, the video monitoring node and the coordinator. Nodes communicate with the coordinator through the Zigbee wireless network. Coordinator communicates with the monitoring center through the GPRS network. The system structure is shown in Fig. 1.

RFID Monitoring Node Design. The RFID monitoring node consists of CC2350 chip, temperature sensor, humidity sensor, keyboard, RFID module and alarm circuit. Its hardware block diagram is shown in Fig. 2. The Zigbee technology is a kind of two-way wireless communication technology with high reliability. It supports star network structure, tree network structure and network structure. The RFID radio frequency identification technology is a non-contact automatic identification technology. It can identify a specific target and read or write data through the radio frequency signal. It has the advantage of easy to use, but the RFID is also insufficient. Active RFID has a far communication distance, but the cost is high. The cost of passive RFID is low, but the 
reading and writing distance is limited. If the system can be combined with Zigbee technology and RFID technology, an efficient wireless sensor network system can be built. It uses RFID technology to identify the goods. It builds the network through Zigbee technology. In this paper, RFID technology and Zigbee technology are combined. It monitors the goods through the RFID module. The temperature and humidity in the logistics vehicle are monitored through temperature sensor and humidity sensor. Between the RFID monitoring node and coordinator, a Zigbee star network based on Zigbee technology is constructed. The monitoring data of logistics vehicle is stored in the memory. At the same time, the monitoring data is transmitted to the coordinator through the Zigbee wireless network. The RFID monitoring node is installed in the interior of the logistics vehicle. According to the needs of logistics vehicles, multiple RFID monitoring nodes can be installed.

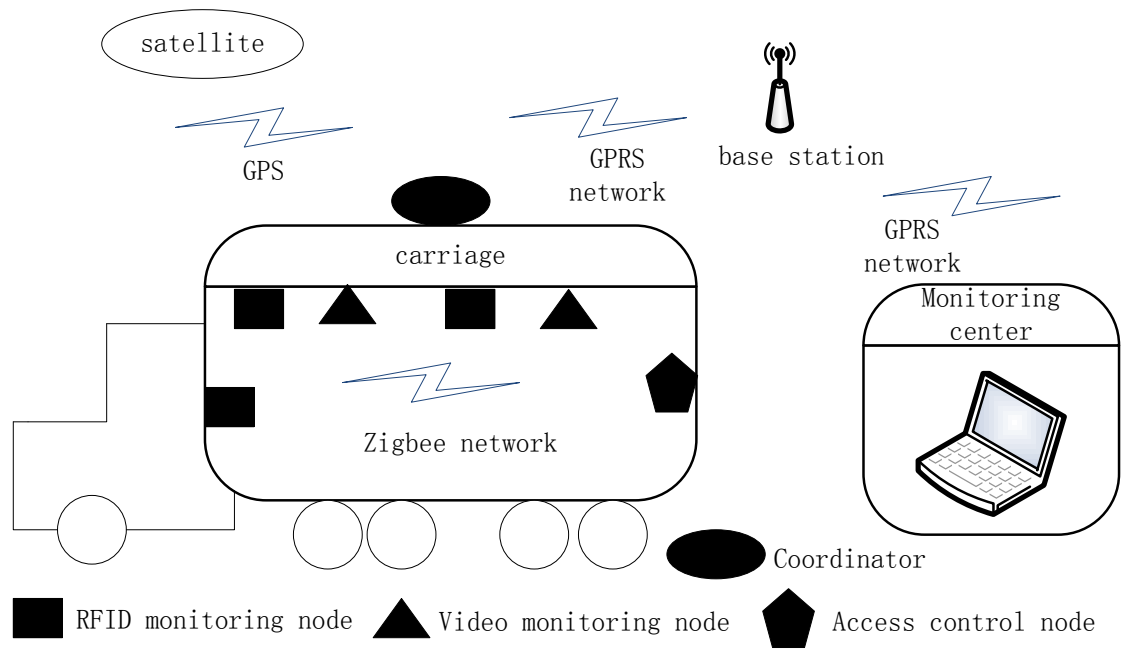

Figure 1. System structure diagram

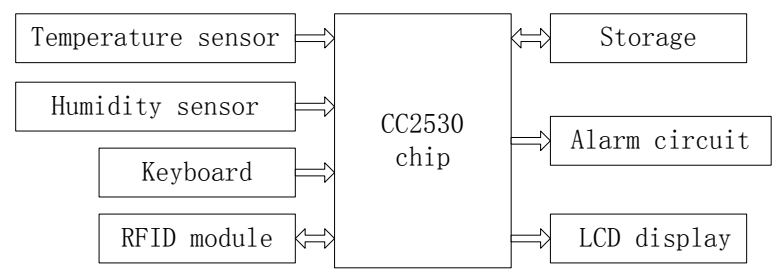

Figure 2. Hardware structure block diagram of RFID monitoring node

Design of Access Control Node. The access control node is consists of CC2530 chip, buttons, gate lock and magnetic sensor. The access control node is installed in the interior of logistics vehicle compartment. The door of carriage is controlled by the access control node. The monitoring center can carry on the remote on and off control to the gate lock which is installed in the carriage. Inside the carriage, you can control the gate lock on or off by pressing the button. In order to effectively reduce and prevent the loss of valuable goods in transit, the monitoring center can remotely control the gate lock to be closed before the vehicle reaches its destination. After reach the destination, the gate lock is controlled to be open by the monitoring center. The role of magnetic sensor is used to detect whether the door is opened. If the door of carriage is opened, the system can make video monitoring of the goods. Monitoring images or photos are stored in the memory.

Design of Video Monitoring Node. The video monitoring node is consists of CC2530 chip, camera driver module, camera and infrared sensor. The video monitoring node is installed in the interior of logistics vehicle compartment. According to the needs of logistics vehicles, multiple video monitoring nodes can be installed. Goods can be photographed regularly by video monitoring node. Photos are stored in the memory. Infrared sensor is used to detect whether there are people inside the carriage. If there are people inside the carriage, the system can make video monitoring of 
the goods. Monitoring images or photos are stored in the memory. If the goods are damaged or lost in transit, monitoring images or photographs can be viewed to find the cause of the damage or loss of the goods.

Coordinator Design. The coordinator is composed of CC2530 chip, GPS module and GPRS module. Coordinator communicates with the monitoring center through the GPRS module. The monitoring data is transmitted to the coordinator through the Zigbee wireless network. After the data is analyzed and processed by the coordinator, the coordinator sends the data to the monitoring center. The GPS information is collected by the coordinator. GPS information is transmitted to the monitoring center and the monitoring nodes.

GPS Module Circuit Design. Monitoring center communicates with the logistics vehicles through the GPRS network. System sends the monitoring data of the goods to the monitoring center through the GPRS network. Monitoring data is analyzed and processed by the monitoring center. If the monitoring data is abnormal, the monitor center sends out the alarm signal and takes the corresponding processing measure. GPS module uses VK1612U7M3L chip. The VK1612U7M3L chip has a full range of positioning functions. It has a high sensitivity. It is widely used in the field of personnel positioning, bus tracking, taxi tracking and positioning and logistics vehicle tracking and positioning. The schematic diagram of the GPS module circuit is shown in Fig. 3.

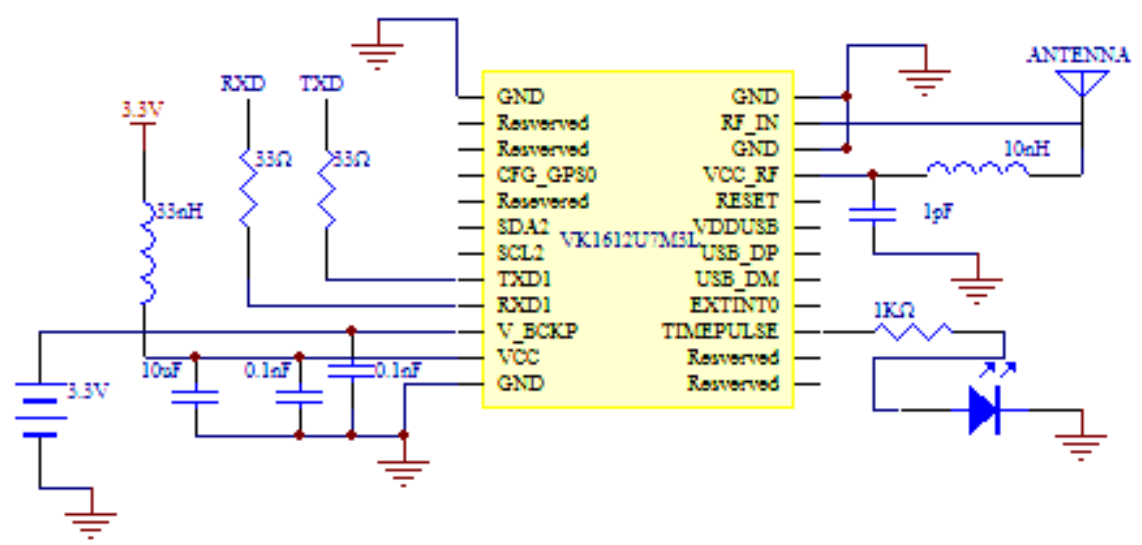

Figure 3. GPS module circuit schematic

\section{System Software Design}

System software design includes RFID monitoring node software design, video monitoring node software design, coordinator software design and monitoring center software design. This paper mainly introduces the software design of RFID monitoring node and monitoring center.

Software Design of RFID Monitoring Node. RFID monitoring node is mainly to monitor the temperature, humidity and goods in the logistics vehicle. The goods are monitored and stored by the system through the RFID module. Monitoring data is analyzed by RFID monitoring node. If the data is abnormal, the RFID monitoring node sends out alarm signal. The monitoring data is transmitted to the coordinator through the Zigbee wireless network. RFID monitoring node programming flow chart is shown in Fig. 4.

Software Design of Monitoring Center. Monitoring center communicates with the logistics vehicles through the GPRS module. GPS information, temperature and humidity inside the carriage, goods information and other information transmitted to the monitoring center through the GPRS network. The monitoring center receives the data and analyses, updates, stores and displays the data. If the monitoring data is abnormal, the monitoring center sends out the alarm signal, and the corresponding processing is done to the abnormal monitoring data. The monitoring center can query the monitoring data of the logistics vehicle at any time by sending the query information to the logistics vehicle. The flow chart of the program design of the monitoring center is shown in Fig. 5. 


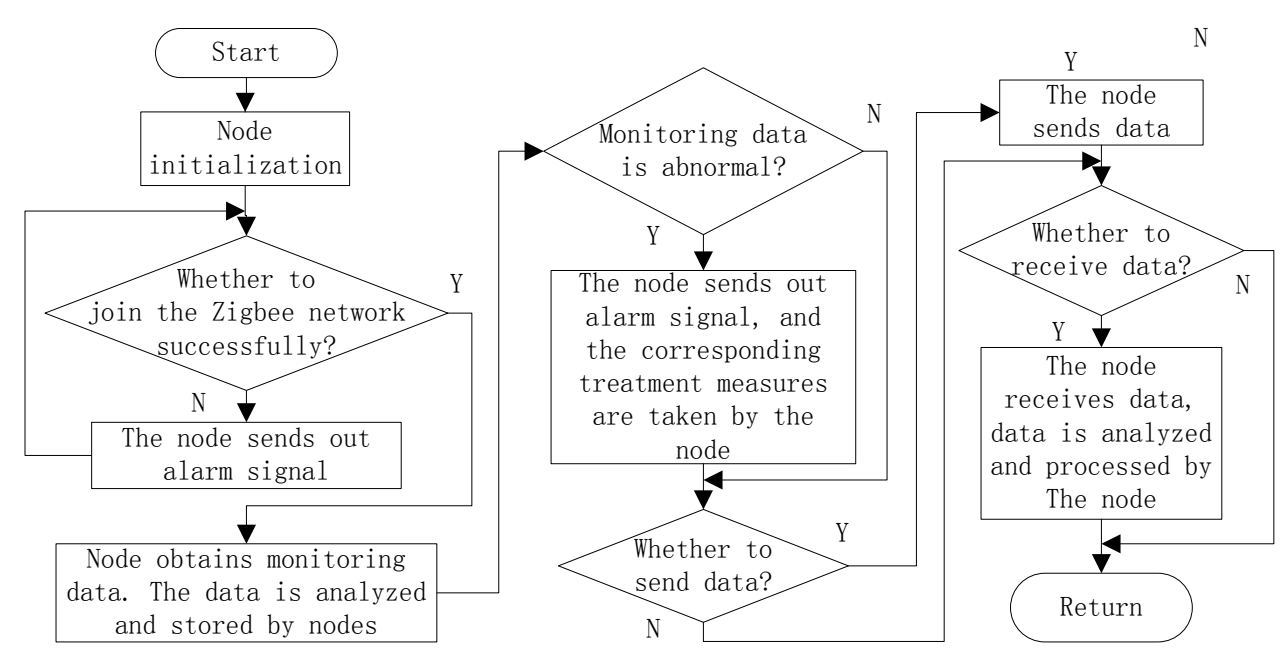

Figure 4. Program flow chart of RFID monitoring node

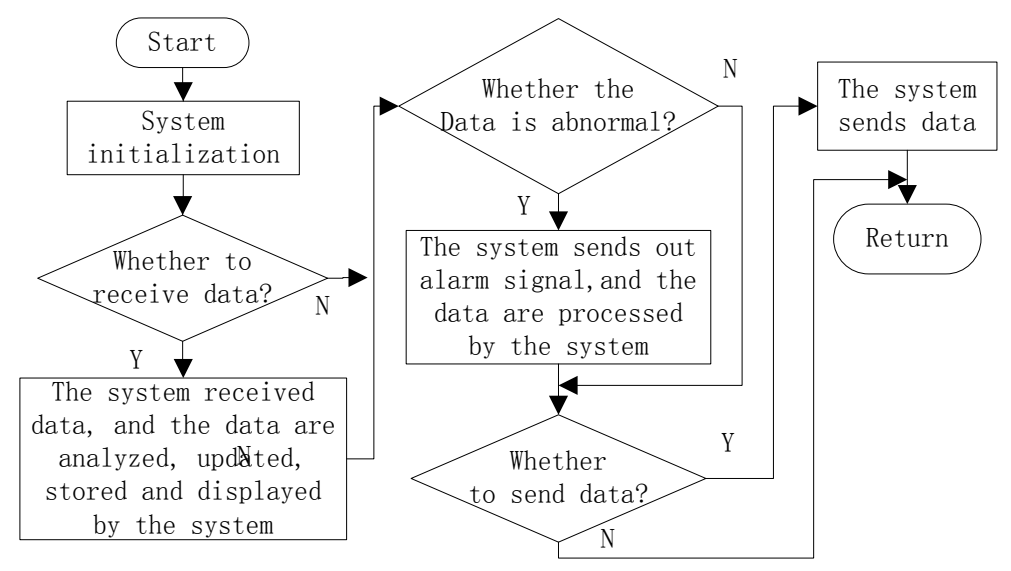

Figure 5. Program flow chart of monitoring center

\section{System Test}

According to the design requirements of the system, the system is installed in a logistics vehicle. Four RFID monitoring nodes, three video monitoring nodes, one access control nodes and one coordinator are respectively installed in the logistics vehicle. The function and performance index of the system are tested in the logistics vehicle terminal and the monitoring center. Test data of the monitoring center are shown in Table 1. The test results show that the function and performance index of RFID monitoring node, video monitoring node and access control node meet the design requirements of the system. Monitoring center can do accurate monitoring of the goods. The system is stable, and the function and performance index of the system meet the design requirements.

\section{Conclusions}

Combined with Zigbee technology, RFID technology, GPS technology and GPRS technology, a logistics monitoring system is designed and implemented. The goods are monitored by the RFID monitoring node through the RFID module. RFID monitoring node, video monitoring node, access control node and coordinator to build a star wireless sensor network through Zigbee technology. In order to effectively reduce and prevent the loss of valuable goods in transit, the monitoring center can remotely control the gate lock to be closed before the vehicle reaches its destination. After reach the destination, the door lock is controlled to be open by the monitoring center. 
Table 1 Test data of monitoring center

\begin{tabular}{ccccc}
\hline Test item & $\begin{array}{c}\text { Monitoring value / } \\
\text { actual value / relative } \\
\text { error (temperature) }\end{array}$ & $\begin{array}{c}\text { Monitoring value / } \\
\text { actual value / relative error } \\
\text { (humidity) }\end{array}$ & $\begin{array}{c}\text { Monitoring value / } \\
\text { actual value / relative } \\
\text { error (quantity of } \\
\text { goods) }\end{array}$ & $\begin{array}{c}\text { Alarm } \\
\text { status }\end{array}$ \\
\hline $\begin{array}{c}\text { The RFID } \\
\text { monitoring } \\
\text { node of } \\
\text { No. } 1\end{array}$ & $32.3^{\circ} \mathrm{C} / 32.3^{\circ} \mathrm{C} / 0.3 \%$ & $65.2 \% \mathrm{RH} / 65.3 \% \mathrm{RH} / 0.15 \%$ & $236 / 236 / 0.0 \%$ & $\begin{array}{c}\text { No } \\
\text { alarm }\end{array}$ \\
\hline $\begin{array}{c}\text { The RFID } \\
\text { monitoring } \\
\text { node of } \\
\text { No. } 2\end{array}$ & $32.7^{\circ} \mathrm{C} / 32.6^{\circ} \mathrm{C} / 0.3 \%$ & $65.5 \% \mathrm{RH} / 65.5 \% \mathrm{RH} / 0.0 \%$ & $265 / 265 / 0.0 \%$ & $\begin{array}{c}\text { No } \\
\text { alarm }\end{array}$ \\
\hline $\begin{array}{c}\text { Access } \\
\text { control } \\
\text { node }\end{array}$ & $\begin{array}{c}\text { success rate of gate } \\
\text { lock control }\end{array}$ & success rate of password setting and updating & \\
\hline
\end{tabular}

The system can make video monitoring of the goods. If the goods are damaged or lost in transit, monitoring images or photographs can be viewed to find the cause of the damage or loss of the goods. Monitoring center communicates with the logistics vehicles through the GPRS network. Goods are monitored in real time by the monitoring center. After testing, the functions and performance indicators meet the design requirements of the system. The system has the advantages of convenient operation and good stability. It has good application prospects.

\section{References}

[1] C. Zhao and S.Y. Chen: Electronic Design Engineering, Vol. 22 (2014) No.5, p.147. (In Chinese)

[2] G.M. Liu and X.D. Sun: Journal of Agricultural Mechanization Research, Vol. 33 (2011) No.4, p.179. (In Chinese)

[3] Y.Y. Sun, H. Yang and Z.H. Liu: Computer Research and Development, Vol. 48 (2011) No.S2, p.343. (In Chinese)

[4] X.F. Luo, X.F. Luo and Y. Liu: Computer Research and Development, Vol. 48 (2011) No.S2, p.362. (In Chinese)

[5] Z. Jiang and D. Liu: ZigBee Technology and Practical Training Course (Tsinghua University press, Chinese 2014), p.120.

[6] Y. Zhang and Y.J. Hu: Journal of Anhui University (Natural Science edition), Vol. 40 (2016) No.2, p.62. (In Chinese)

[7] J.Z. Du and H. Liu: ZigBee Technical Principle and Actual Combat (Mechanical Industry Press, Chinese 2015), p.92.

[8] H.H. Shui: Software Guide, Vol. 13 (2014) No.4, p.118. (In Chinese)

[9] C.H. Chen and W.B. Wei: Computer Measurement and Control, Vol. 19 (2011) No.6, p.1361. (In Chinese)

[10]Z.M. Li and Y.D. Zhao: Modern Electronic Technology, Vol. 28 (2015) No.4, p.66. (In Chinese) 